\title{
Salmeterol with fluticasone enhances the suppression of IL-8 release and increases the translocation of glucocorticoid receptor by human neutrophils stimulated with cigarette smoke
}

\author{
Esmaeil Mortaz • Mehdi Vaezi Rad • \\ Malcolm Johnson • Danielle Raats • Frans P. Nijkamp • \\ Gert Folkerts
}

Received: 20 October 2007 /Revised: 11 April 2008/Accepted: 16 April 2008/Published online: 4 July 2008

(C) The Author(s) 2008

\begin{abstract}
The combination of inhaled corticosteroids and long-acting $\beta_{2}$-adrenoceptor agonists is increasingly used in chronic obstructive pulmonary disease (COPD). Recently, we have demonstrated that combination of salmeterol and fluticasone propionate (FP) additionally suppress the production of IL-8 by human monocyte. In this study, the molecular mechanism behind the effectiveness of this combination therapy is investigated in human neutrophils. Human neutrophils were preincubated with salmeterol or FP or the combination. The amount of interleukin-8 (IL-8), elastase and matrix metalloproteinases (MMP)-2 and -9 releases, and reactive oxygen species (ROS) generation and expression of MAP kinase phosphatase (MKP-1) and glucocorticoid receptor (GR) were determined. Cigarette smoke medium (CSM) induces an increased expression of CXC receptors and the production of ROS that may explain the strong production of IL- 8 by neutrophils. The expression of CXC receptors, the production of ROS, and the release of elastase and MMP-2 and -9 were not influenced
\end{abstract}

E. Mortaz $(\triangle) \cdot$ M. V. Rad $\cdot$ D. Raats $\cdot$ F. P. Nijkamp $\cdot$ G. Folkerts Division of Pharmacology and Pathophysiology,

Utrecht Institute for Pharmaceutical Sciences, Faculty of Sciences, Utrecht University,

P.O. Box 80082, 3508 TB Utrecht, The Netherlands

e-mail: e.mortaz@uu.nl

\section{E. Mortaz}

Department of Basic Science, Section of Biochemistry,

Faculty of Veterinary Medicine, Urmia University,

Urmia, Iran

M. Johnson

Respiratory Science, GlaxoSmithKline,

Greenford, Middlesex, UK

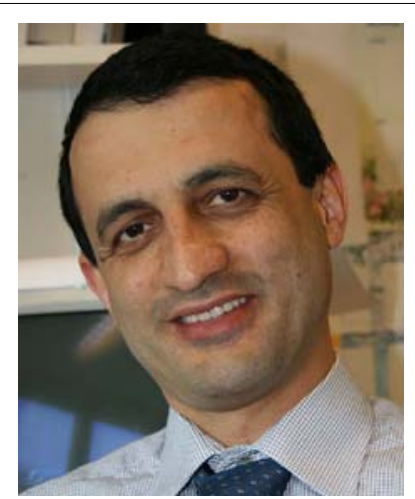

ESMAEIL MorTaz

received his Ph.D. in 2005 in Molecular Biology and Biochemical Sciences from the Faculty of Pharmacy, Utrecht University, The Netherlands. He is currently a Post doc fellow at the University of Utrecht, The Netherlands. His research is focused on the effect of cigarette smoke on Toll-like receptors on neutrophils and dendritic cells and their role in the development of lung diseases and COPD.

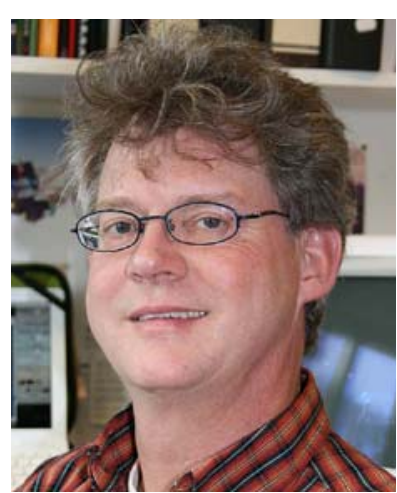

Gert FolKers

started in the Rudulf Magnus Institute (Faculty of Medicine) at the Utrecht University in 1981. Worked for 6 years in the Department of Pharmacology (Faculty of Veterinary Sciences), did his thesis on viral infections and asthma (1991) and is appointed in 2003 as full professor in the department of Pharmacology and Pathophysiology (Utrecht Institute for Pharmaceutical Sciences) investigating the pathophysiology of lung diseases. by salmeterol, FP, or the combination. Interestingly, the combination therapy had an additive suppressive effect on the CSM-induced production of IL-8. The latter could be explained by an increased mRNA expression of MKP-1, the GR and an increased translocation of the GR to the nucleus. This leads eventually to suppression of both the 
NF- $\mathrm{KB}$ and MAPK pathways and, hence, to less IL8 production by the neutrophil. These data are in support for the use of a combination therapy in COPD patients.

Keywords Glucocorticoids · Neutrophil · Chemokine

$\begin{array}{ll}\text { Abbreviations } \\ \text { CSM } & \text { cigarette smoke medium } \\ \text { GR } & \text { glucocorticoid receptor } \\ \text { FP } & \text { fluticasone propionate } \\ \text { FPS } & \text { fluticasone propionate plus salmeterol } \\ \text { HRP } & \text { horse radish peroxidase } \\ \text { PMN } & \text { polymorpho-nuclear cells } \\ \text { MIP } & \text { macrophage inflammatory protein } \\ \text { MMPs } & \text { matrix metalloproteinases } \\ \text { MKP-1 } & \text { MAPK phosphatase-1 (MPK-1) } \\ \text { NAC } & N \text {-acetyl-cysteine }\end{array}$

\section{Introduction}

Chronic obstructive pulmonary disease (COPD) is a major and increasing global health problem [1]. COPD has a complex underlying pathophysiology involving inflammatory and structural cells, all of which have the capacity to release multiple inflammatory mediators. Cigarette smoke (CS) has been considered a major player in the pathogenesis of COPD $[2,3]$. Exposure to CS activates an inflammatory cascade in the airways resulting in the production of a number of potent cytokines and chemokines such as interleukin-8 (IL-8), with accompanying damage to the lung epithelium, increased permeability, and recruitment of macrophages and neutrophils [4]. Several inflammatory cells, both of the innate and adaptive immune system, participate in the inflammatory response in COPD including neutrophils, macrophages and $\mathrm{CD} 8^{+}$lymphocytes [5]. Matrix metalloproteases (MMPs), which are mainly secreted by neutrophils, have the enzymatic capacity to cause morphological changes in the lungs and contribute significantly to the pathogenesis of COPD [6-8]. Increased concentrations of MMP-1, $-2,-9$, and -12 have been found in bronchoalveolar lavage samples of COPD patients [9].

Therapeutic agents prevent and control symptoms, reduce exacerbations, increase exercise tolerance, and improve health status $[10,11]$. Long-acting $\beta_{2}$-adrenergic agonists (LABAs, such as salmeterol) combine symptom control with improvement in lung function and provide clinically relevant improvements in health status. Inhaled corticosteroids (ICS) are recommended for the treatment of patients with a more severe disease and frequent exacerbations, and inhalation of the combination of LABAs and
ICS is more effective in improving lung function and symptoms and reducing exacerbations than either drug alone [12, 13]. Moreover, recently, it has been demonstrated that LABAs can enhance the anti-inflammatory action of GCs. Unfortunately, the exact mode of action of the combination of these drugs is not well documented. Recently, we have demonstrated that combination of salmeterol and FP additively suppressed of CS-induced IL-8 production in human monocytes [14]. In the current study, we investigate the effectiveness of salmeterol, fluticasone propionate (FP), or the combination on the release of proteases and IL- 8 induced by cigarette smoke medium (CSM) from neutrophils. The mechanism of action at the level of the glucocorticoid receptor (GR) and gene transcription was studied.

\section{Materials and methods}

Chemicals and reagents

FP and salmeterol were obtained from GlaxoSmithKline (Greenford, UK). Fluticasone was dissolved in dimethylsulfoxide and salmeterol in ethanol at a concentration of $10^{-3} \mathrm{M}$, for further dilution to yield final chosen concentrations. Lipopolysaccharide (LPS), penicillin, streptomycin, 1-glutamine, sodium pyruvate, 2-mercaptoethanol, and $\mathrm{N}$-acetyl-cysteine (NAC) were purchased from Sigma (Sigma-Aldrich, Zwijndrecht, The Netherlands). SN50, a cell-permeable, inhibitory peptide of the nuclear translocation of nuclear factor-kappa B (NF-KB), was purchased from Calbiochem (VWR International BV, The Netherlands). The enzyme-linked immunosorbent assay (ELISA) kits for human IL-8 were purchased from Biosource (BioSource, Breda, The Netherlands). SB 203580 and curcumin were obtained from Invivogen (InvivoGen Europe, Toulouse, France). Rabbit polyclonal antibody against IkB- $\alpha$, mouse monoclonal antibody against GR $\alpha$ (P-20, which is detected GR $\alpha$ ), rabbit polyclonal antibody against actin, rabbit polyclonal antibody against lamin A (H-102), and mouse monoclonal antibody against phospho $\mathrm{p} 38$, rabbit antibody against $\mathrm{p} 38$, rabbit monoclonal antibody c-fos and Phosphop44/42 MAPK (Thr202/Tyr204), mouse monoclonal antibody Erk1/2 were obtained from Santa Cruz Biotechnology (Tebu-bio, Heerhugowaard, The Netherlands) and Cell Signaling technology (BIOKÉ, The Netherlands), respectively.

Cell culture

Isolation of polymorpho-nuclear cells (PMN) was carried out as described before [15]. Briefly, PMN were isolated from the buffy coat (supplied by Blood Bank, Sanquine, 
The Netherlands) prepared from healthy nonsmoker donors.

Heparinized blood was mixed $1: 1$ with $0.9 \%$ sodium chloride containing 3.0\% dextran T-500 (Amersham Biosciences) and then incubated for $20 \mathrm{~min}$ at room temperature to sediment erythrocytes. The resulting leukocyte-rich supernatant was centrifuged at $670 \times \mathrm{g}$ for $10 \mathrm{~min}$, and cells were resuspended in $35 \mathrm{ml}$ of $0.9 \%$ sodium chloride. The leukocyte suspension was underlayed with $10 \mathrm{ml}$ of Ficoll-PaquePLUS (1.077 g/l, Amersham Biosciences) and centrifuged for $25 \mathrm{~min}$ at $350 \times \mathrm{g}$ to separate neutrophils from peripheral blood mononuclear cells. Peripheral blood mononuclear cells were aspirated from the FicollPaquePLUS-saline interface, and sides of the gradient tubes were wiped with sterile cotton swabs to remove any residual cells. After standard hypotonic lysis of erythrocytes, purified PMN were suspended in Roswell Park Memorial Institute (RPMI) 1640 medium buffered with $10 \mathrm{mM}$ 4-(2-hydroxyethyl)-1-piperazineethanesulfonic acid (HEPES), pH 7.2 and placed on ice until used. The cells consisted of more than $95 \%$ neutrophils and were more than $99 \%$ viable, as determined by trypan blue exclusion (for viability) and flow cytometry by using $\mathrm{CD} 16^{+}$antibody (for purity). For simplicity, the terms neutrophil and PMN are used interchangeably. All reagents used contained $<25.0 \mathrm{pg} /$ $\mathrm{ml}$ endotoxin (limulus amebocyte lysate assay, Fisher).

\section{CS media preparation}

CSM was prepared as described before [16, 17]. CSM was generated by the burning of commercially available Lucky Strike cigarettes without filter (British-American Tobacco, Groningen, The Netherlands), using the TE-10z smoking machine (Teague Enterprises, Davis, CA, USA), which is programmed to smoke cigarettes according to the Federal Trade Commission protocol (35-ml puff volume drawn for $2 \mathrm{~s}$, once per minute) [18]. Briefly, this machine was used to direct main- and sidestream smoke from one cigarette through a 5-ml culture medium (RPMI without phenol red). Hereafter, absorbance was measured spectrophotometrically, and the media were standardized to a standard curve of $\mathrm{CSM}$ concentration against absorbance at $320 \mathrm{~nm}$. The $\mathrm{pH}$ of the resultant extract was titrated to $\mathrm{pH} 7.4$ and diluted with medium. This concentration (optical density [OD]= 4.0) was serially diluted with untreated media to $0.03,0.06$, 0.1 , and $0.2 \mathrm{OD}$ and applied to the cells. Except for the dose-response and viability test, CSM at a concentration of 0.06 OD was selected for use in all experiments.

Solutions ranging from 0.0075 to 0.12 were used in the present study after preliminary experiments, which indicated that these were nontoxic concentrations (viability $\geq 96 \%$ ). Toxic concentrations of CSM were detected performing different toxicological assays (lactate dehydrogenase) and fluorescence-activated cell sorting (FACS) analysis (annexin-V and 7-AAD staining).

Cell activation

PMN were activated by CSM with different concentration at various time points. As positive control cells were activated with LPS $(1 \mu \mathrm{g} / \mathrm{ml})$. The production of MMP-2, MMP-9, elastase, and IL-8 were measured after a 9-h stimulation in supernatants of cells. Cells were pretreated with salmeterol and FP alone or in the combination of various concentrations for $90 \mathrm{~min}$ and then activated with CSM (0.06 OD) or LPS for (a) $30 \mathrm{~min}$ to determine protein expression in the cytoplasmic and the nuclear fractions and (b) $9 \mathrm{~h}$ for detection of IL-8 and MMPs from cell supernatants.

\section{Mediators assays}

ELISA tests for IL-8, MMP-2, and MMP-9 detected were carried out according to the manufacturer's instructions of kits (R\&D systems).

\section{Fluorescence-activated cell sorting}

Because the CXCR1 and CXCR2 are main receptors for IL-8 in many cell types [19], therefore we tested whether CSM can modulate the surface expression of these receptors on PMN. In this experiment, the surface expression of CXCR1 and CXCR2 was measured by FACS analysis. PMN were pretreated and stimulated with CSM or LPS as described before, and, then, after washing twice with FACS buffer (fetal calf serum $1 \%$, phosphate-buffered saline (PBS), and $0.01 \%$ sodium azide), the cells were incubated with the PElabeled CXCR1 and CXCR2 antibodies for $30 \mathrm{~min}$, and the expression of CXCR1 and CXCR2 was measured by FACS calibor (BD Biosciences). Geometric mean-fluorescence intensity (MFI) ratio was calculated by dividing the geometric mean-fluorescence intensity of test $\mathrm{mAb}$ with the MFI of a corresponding isotype-matched control antibody.

\section{Measurement of intracellular ROS}

Intracellular reactive oxygen species (ROS) levels were measured by flow cytometry in cells cultured in serum-free medium and loaded with the redox-sensitive dye DCFHDA (D399, Invitrogen) [20].

Neutrophil viability

PMN viability was assessed by flow cytometry immediately after staining with propidium iodide or 7-A-DD/Anexin $\mathrm{V}$ (BD, Pharmingen). 


\section{RT-PCR for GR $\alpha$ and MKP-1}

Cells were pretreated for 15 min with salmeterol or FP and then stimulated with cigarette smoke extract (CSE) for $30 \mathrm{~min}$, followed by harvesting of the cells by centrifugation. Total cellular RNA was isolated from frozen samples using Qiagen's RNeasy kit. Total RNA preparation, cDNA synthesis, and polymerase chain reaction (PCR) were conducted, as described before [21]. (RT)-PCR was performed on $1 \mu \mathrm{g}$ of each RNA sample using Invitrogen One-Step RT-PCR Kit and the following gene-specific primer pairs as described before [22, 23].

Preparation of cytoplasmic and nuclear extracts

Cells were washed twice with PBS and allowed to equilibrate for $5 \mathrm{~min}$ in ice-cold cytoplasmic extraction reagent (Pierce) containing protease inhibitors (Roche). Cells were lyzed, and cytoplasmic and nuclear fractions were subjected to Western blotting as described before [21].

\section{Western blot analysis}

After activation, cells were washed once with PBS and lyzed in lysis buffer containing $1 \%$ Triton X-100 or NP-40, $\mathrm{NaCI}$, Tris, and MiniTM protease inhibitors. The protein concentration was determined by BCA protein assay kit (Pierce). The lysates $(25$ or $50 \mu \mathrm{g}$ ) were subjected to sodium dodecyl sulfate-polyacrylamide gel electrophoresis $[10 \%(w / v)$ gel] as described before [21].
Quantification of NF- $\mathrm{BB}$ activity

NF- $\mathrm{KB}$ activity was analyzed by using the Trans-AM NFkB p65/NF-kB p50 Transcription Factor Assay Kit (Active Motif, Rixensart, Belgium), according to the manufacturer's instructions. Briefly, $2 \mu \mathrm{g}$ of the nuclear extracts was incubated with an oligonucleotide containing the NF-KB consensus site bound to a 96-well plate. After extensive washes, the NF- $\mathrm{KB}$ complexes bound to the oligonucleotide were incubated with an antibody directed against the NF$\mathrm{KB}$ p65 subunit at a dilution 1:1,000. After washes, the plates were subsequently incubated with a secondary antibody conjugated to horseradish peroxidase $(1: 1,000)$, and the peroxidase reaction was quantified at $450 \mathrm{~nm}$ with a reference wavelength of $655 \mathrm{~nm}$.

\section{Statistical analysis}

Statistical significance was assessed by one-way analysis of variance, and differences were pinpointed by StudentNewman-Keuls' multiple range test.

\section{Results}

CSM induces of IL-8, elastase, and MMPs

Neutrophils were exposed to CSM for $9 \mathrm{~h}$. CSM concentration dependently induces the production of IL-8 (Fig. 1a). Significant amounts of IL-8 were already produced by 0.015 OD of CSM with an optimum at a concentration of
Fig. 1 CSM induces the release of mediators by human neutrophils. Neutrophils were isolated from buffy coats and incubated for $9 \mathrm{~h}$ with various concentration of CSM. The production of IL-8 (a), elastase (b), and MMP2 (c) and MMP-9 (d) was determined by ELISA kits. Data shown are mean \pm SEM of three independent experiments. The asterisks represent significant differences compared with cells not exposed to CSM $\left({ }^{*} p<0.05\right.$; $* * p<0.01 ; * * * p<0.001$ )
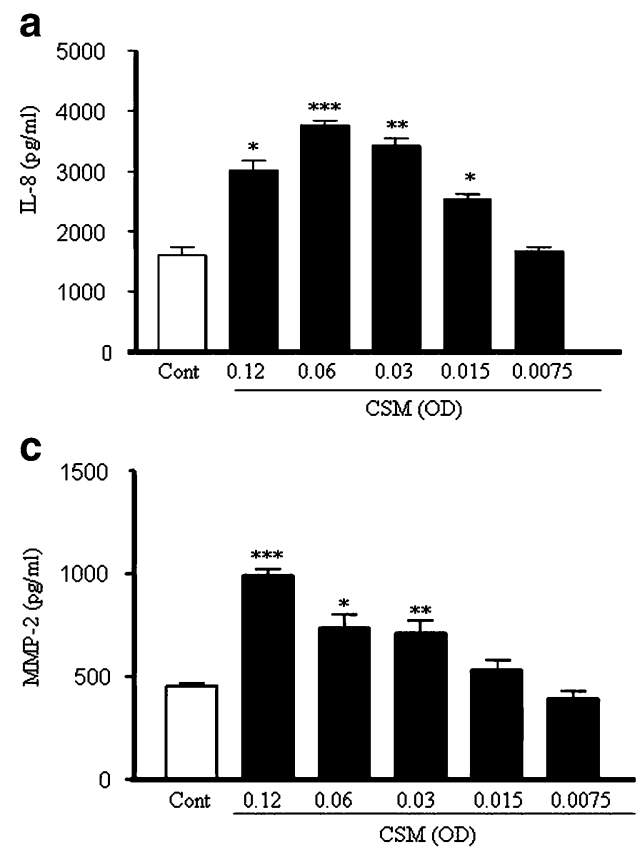

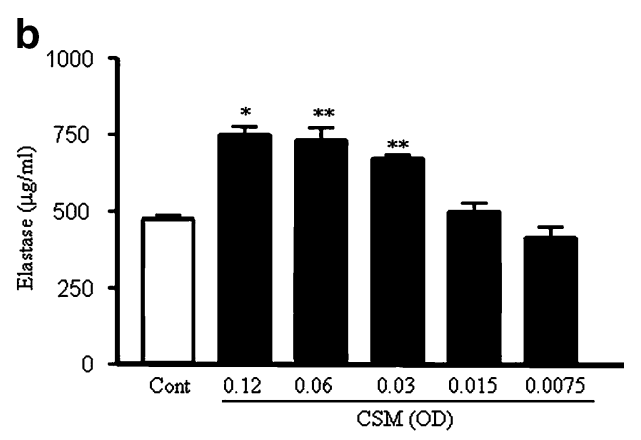

d

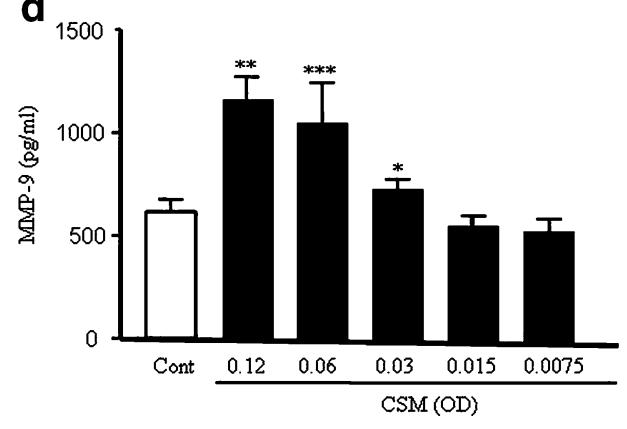


0.06 OD. Interestingly, CSM also induced the release of elastase and MMP-2 and -9 in a concentration-dependent manner (Fig. 1b-d). To assess the viability of cells exposed to CSM, FACS analysis with propidium iodide was performed. CSM was cytotoxic at concentration $\geq 0.12$ OD, and almost $60 \%$ of the cells was killed by 0.24 OD of CSM as compared to control cells. For this reason, a concentration of CSM (0.06 OD) was chosen for all future experiments.

Salmeterol and FP additively suppresses the release of IL-8

Pre-incubation of PMN with FP $\left(10^{-11}, 10^{-7} \mathrm{M}\right)$ or salmeterol $\left(10^{-9}, 10^{-5} \mathrm{M}\right)$ dose-dependently suppress the IL-8 production induced by CSM (Fig. 2a,b). Combination of salmeterol $\left(10^{-8}, 10^{-7} \mathrm{M}\right)$ and $\mathrm{FP}\left(10^{-10}-10^{-8} \mathrm{M}\right)$ induces further suppression of IL-8 releases (Fig. 3b-e,g). Moreover,
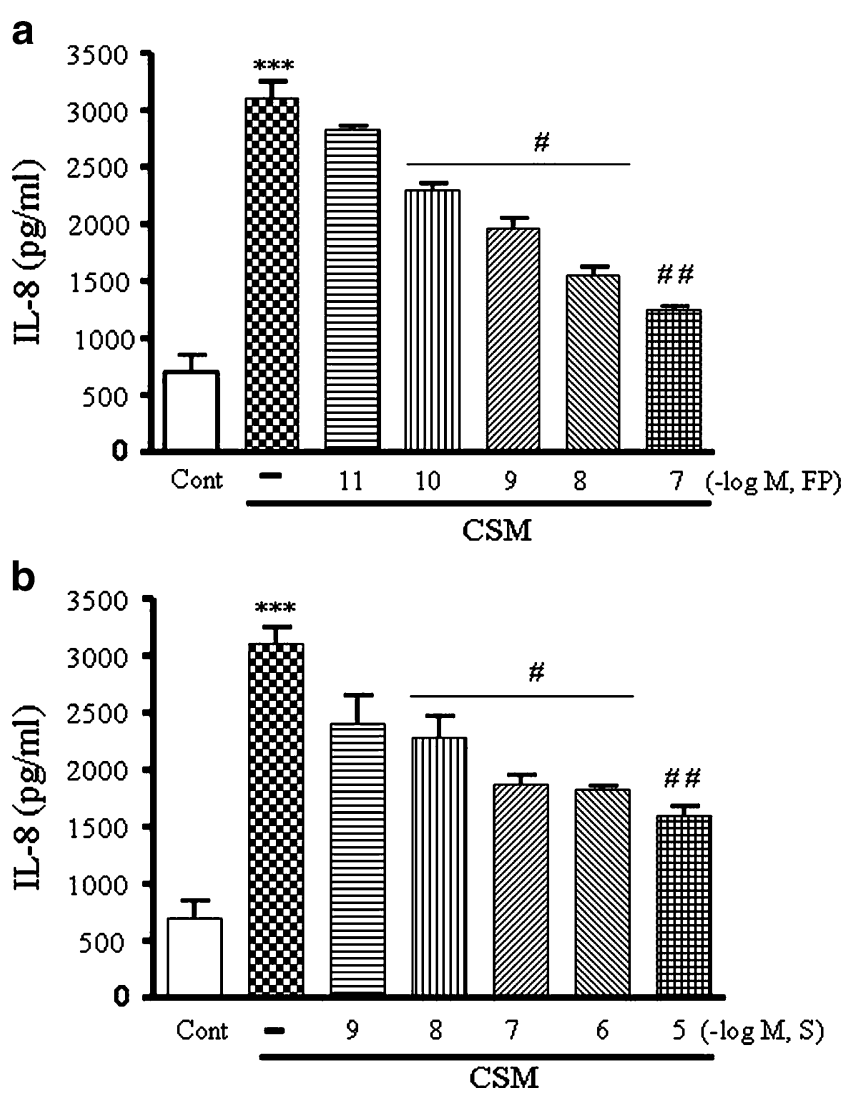

Fig. 2 Salmeterol and FP suppress IL-8 release induced by CSM neutrophils were isolated from buffy coats and pretreated for $90 \mathrm{~min}$ with FP $10^{-11}-10^{-7} \mathrm{M}$ (a) or salmeterol $10^{-9}-10^{-5} \mathrm{M}(\mathbf{b})$ and then stimulated for $9 \mathrm{~h}$ with CSM (0.06 OD) The supernatants were harvested and subjected to ELISA methods as described on "Materials and methods". Data shown are mean \pm SEM of three independent experiments. Asterisk indicates significant differences between medium-treated cells and cells treated with CSM $(* * * p<0.0001)$ and number sign represents the significance between cells treated with CSM alone and CSM with S or FP $\left({ }^{\#} p<0.05\right.$ and ${ }^{\# \#}$ p $\left.<0.01\right) . S$ and FP indicate salmeterol and $\mathrm{FP}$, respectively a

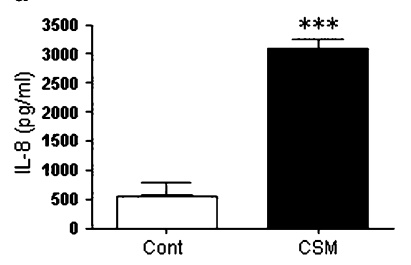

b
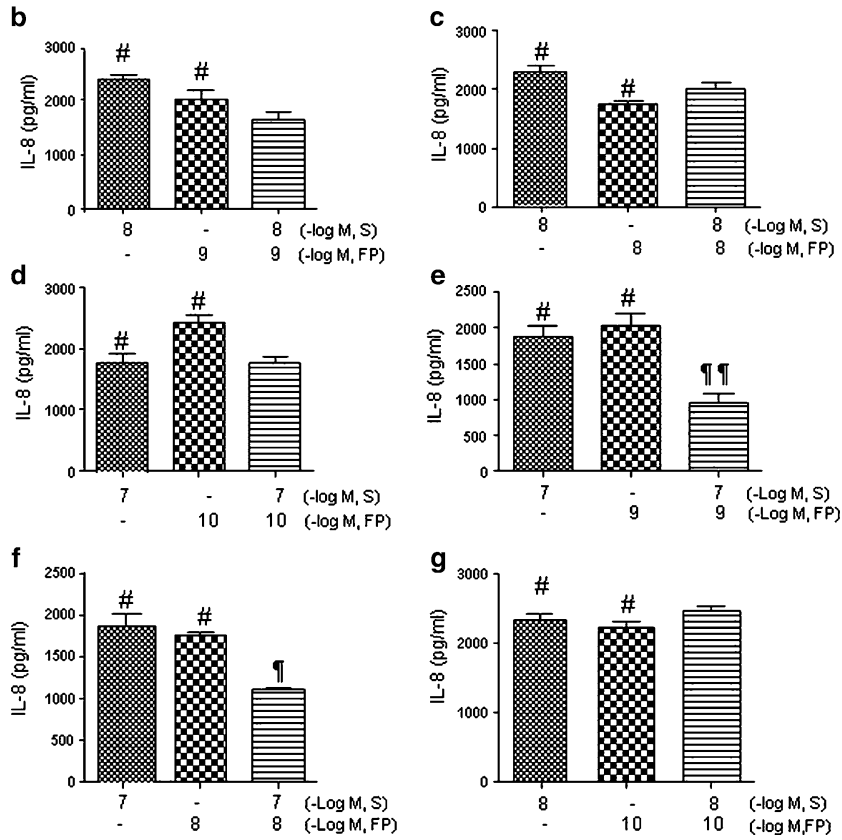

Fig. 3 Salmeterol and FP in combination have additive effects on suppression of IL-8 release induced by CSM. Neutrophils were isolated from buffy coats and treated with CSM (a) or pretreated for 90 min with salmeterol $\left(10^{-8}\right.$ and $\left.10^{-7} \mathrm{M}\right)$ and $\mathrm{FP}\left(10^{-10}-10^{-8} \mathrm{M}\right)$ with selected combinations and then stimulated for $9 \mathrm{~h}$ with CSM $(0.06$ $\mathrm{OD} ; \mathbf{b}, \mathbf{c}, \mathbf{d}, \mathbf{e}, \mathbf{f}$, and $\mathbf{g})$. The supernatants were harvested and subjected to ELISA methods as described on "Materials and methods." Data shown are mean \pm SEM of three independent experiments. Asterisk indicates significant differences between mediumtreated cells and cells treated with CSM $(* * * p<0.0001)$, Number sign represents the significance between cells treated with CSM alone and CSM with salmeterol or FP $\left({ }^{\#} p<0.05\right.$ and $\left.{ }^{\# \#} p<0.01\right)$ and paragraph mark represents significant differences between salmeterol, FP alone, and in combination $\left({ }^{\pi} p<0.05\right.$ and $\left.{ }^{\top} \mathrm{P}<0.01\right) . S$ and $F P$ indicate salmeterol and FP, respectively

as shown in Fig 3e, salmeterol $\left(10^{-7} \mathrm{M}\right)$ and FP $\left(10^{-9} \mathrm{M}\right)$ in combination had a clear additive effect on the suppression of IL-8 releases by more than $60 \%(P<0.05$ compared with salmeterol and FP alone). Neither salmeterol or FP or the combinations were able to prevent the CSM-induced release of elastase or MMP-2 and MMP-9 (data not shown). Higher concentration of salmeterol and/or FP is/are most likely to be cytotoxic.

\section{Surface expression of CXCR1 and CXCR2}

IL-8 may stimulate its own release via stimulation of CXCR1 or CXCR2 receptors. Moreover, CSM might 
increase the surface expression of these receptors by which additional IL- 8 could be released. Therefore, we determined the surface receptors expression after stimulation of neutrophils with CSM with or without salmeterol and/ or FP. CSM (0.06 OD) increases the expression of CXCR1 and CXCR2 after a 4-h exposure (Fig. 4). Similar results were obtained when the cells were exposed to CSM overnight. Pretreatment of the cells with salmeterol $10^{-7} \mathrm{M}$ ) or FP $\left(10^{-9} \mathrm{M}\right)$ or the combination for $4 \mathrm{~h}$ or overnight did not affect the CSM-induced increase of the CXCR1 and CXCR2 receptors (data not shown).

\section{IL-8 and ROS production}

CS is a complex insult consisting of more than 4,000 different components [24] that may directly or indirectly induce the production of ROS. ROS may activate intracellular pathways that could induce the IL-8 production. Indeed, NAC had a marked inhibitory effect on CSMinduced IL-8 production (Fig. 5a). Therefore, ROS production was measured after stimulation with PMA or CSM. Although the CSM-induced ROS production was less than observed with PMA, it was still doubled compared to the basal production (Fig. 5b). The combination therapy (salmeterol and FP) had no effect on CSM-stimulated ROS production. Interestingly, NAC completely prevented the PMA- and CSM-induced ROS.
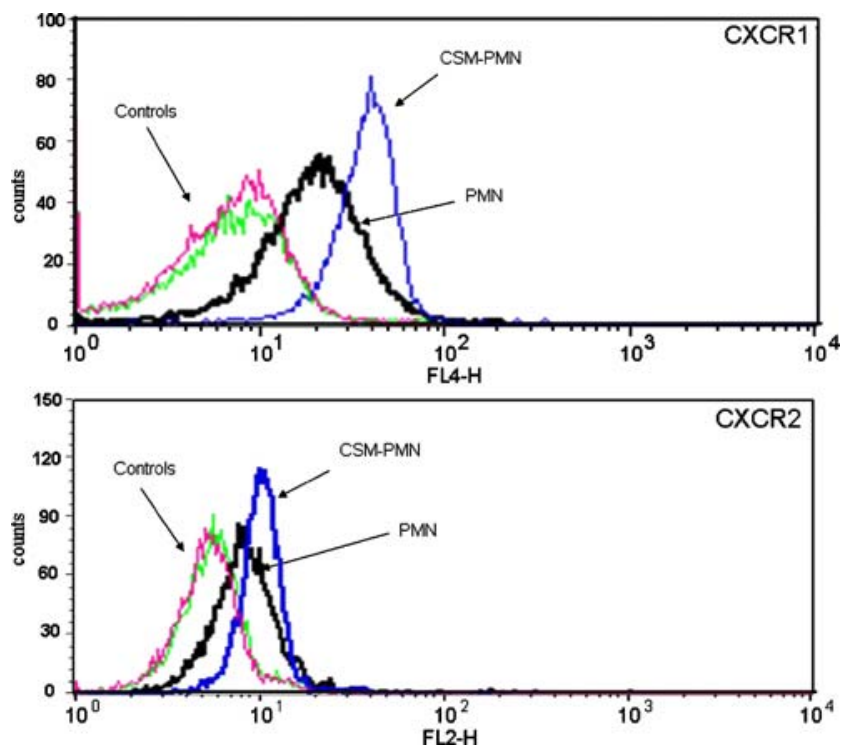

Fig. 4 Modulation of CXCR1 and CXCR2 receptor expressions by CSM. Neutrophils were isolated from buffy coats and treated with $\mathrm{CSM}$ for $5 \mathrm{~h}$ and then stained with CXCR1 and CXCR2 conjugated with PE Abs for $30 \mathrm{~min}$ before measuring receptor expression by flow cytometry. The data were calculated by MFI for CXCR1 and CXCR2 in CD16-gated cells. The experiment shown is representative of six independent experiments
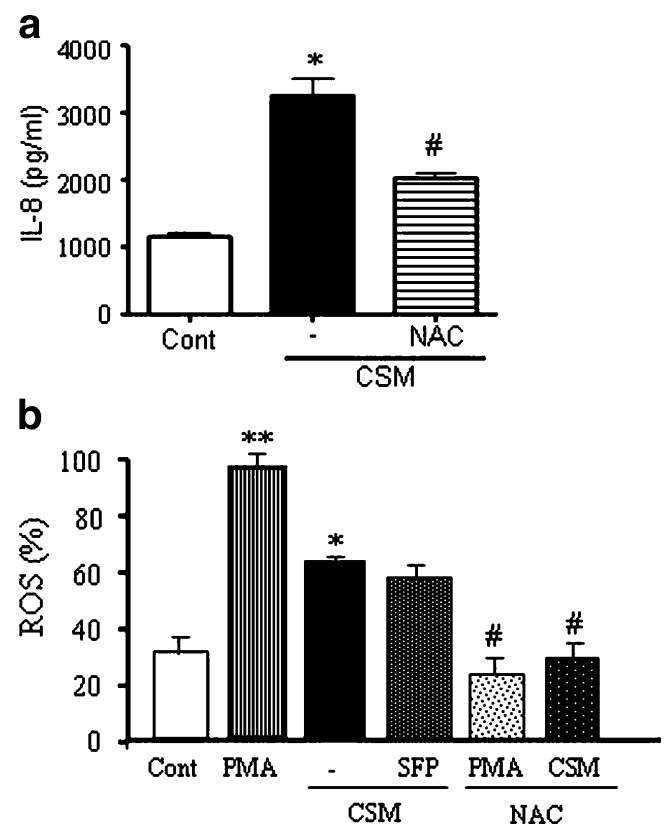

Fig. 5 CSM induces the production of ROS. a Neutrophils were incubated with CSM $(0.06 \mathrm{OD})$ or pretreated with NAC $(0.1 \mathrm{mM})$ for $30 \mathrm{~min}$ and then stimulated with CSM for $9 \mathrm{~h}$, and the production of IL-8 was determined in the supernatants. Asterisk indicates significant differences between medium-treated cells and cells treated with CSM $\left({ }^{*} p<0.05\right)$, and the number sign represents the significance between cells treated with CSM and cells treated with NAC and CSM $\left({ }^{\#} p<\right.$ 0.05). b Neutrophils were incubated with CSM (0.06 OD), PMA $(1 \mathrm{nM})$ or pretreated with salmeterol $\left(10^{-7}\right)$, FP $\left(10^{-9} \mathrm{M}\right)$, and then activated with CSM for $5 \mathrm{~h}$, and ROS generation was assayed by incubation of the cells with $\mathrm{CM}-\mathrm{H}_{2}$ DCFDA $(10 \mu \mathrm{mol} / 1)$ oxidationbased fluorescence and analyzed by FACS analysis. Each sample was normalized using an appropriate unstained control, and the figure shows a mean-fold increase to control \pm SEM. Asterisk indicates significant differences between medium-treated cells and activated cells with PMA and CSM $\left({ }^{*} p<0.05,{ }^{* *} p<0.01\right)$, and the number sign represents the significant differences between cells treated with PMA or CSM and cells pretreated with NAC and stimulated with PMA or CSM $\left({ }^{\#} p<0.05\right)$

Pharmacological modulation of molecular mechanisms

To gain insight to the mechanism behind the CSM-induced IL-8 production, we applied pharmacological agents to block the NF-kB, MAPK and p38 pathways (see Fig. 9). As demonstrated in Fig. 6, the release of IL-8 by CSM was dependent on all three pathways, i.e., curcumin $(25 \mu \mathrm{M})$ and SN50 $(100 \mu \mathrm{g} / \mathrm{ml})$ as inhibitors of NF- $\mathrm{kB}, \mathrm{SB} 239063$ $(5 \mu \mathrm{M})$ as an inhibitor of $\mathrm{p} 38$ MAP kinase, and PD98059 $(50 \mu \mathrm{M})$ as an inhibitor of Erk1/2. We tested the viability of cells after treatment of each pharmacologic inhibitor; none of them was cytotoxic as indicated doses.

MAP kinase and NF-KB pathways

Based on the results described above, it was investigated whether downstream molecules such as NF-KB and MAP 


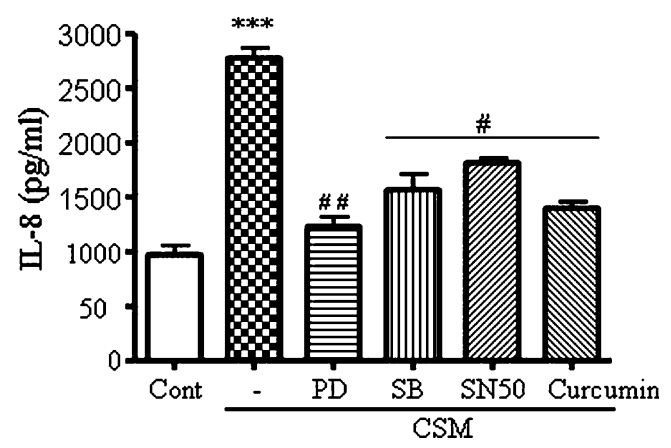

Fig. 6 Pharmacaological inhibition of NF-kB and MAPK pathways. Neutrophils were pretreated with PD98059 $(50 \mu \mathrm{M})$, SB $239063(5$ $\mu \mathrm{M})$, curcumin $(25 \mu \mathrm{M})$ and SN50 $(100 \mu \mathrm{g} / \mathrm{ml})$ for $30 \mathrm{~min}$ and then activated for $9 \mathrm{~h}$ with CSM (0.06 OD). Culture supernatants were then tested for IL- 8 production by ELISA. Data are the mean \pm SEM of four independent experiments with triplicate dishes. Asterisk indicates significant differences between medium-treated cells and cells treated with CSM $(* * * p<0.0001)$, and the number sign represents the significance differences between cells treated with CSM and cells pretreated with inhibitors and CSM $\left({ }^{\#} p<0.05\right.$ and $\left.{ }^{\# \#} p<0.01\right)$

kinase(s) signaling (Fig. 9) could be modulated by CSM and salmeterol and/or FP. Salmeterol and FP alone slightly and, by combination, significantly suppresses phosphorylation of Erk1/2 (Fig. 7a). In addition, both compounds decreased the phosphorylation of $\mathrm{p} 38$ and cfos. Interestingly, the combination of salmeterol and FP abrogates the phosphorylation of p38, c-fos nearly completely (Fig. 7a).

Moreover, CSM induced the degradation of IKB- $\alpha$ in cytoplasm and increases the translocation of p65 in nuclear fraction (Fig. $7 \mathrm{~b})$. Salmeterol $\left(10^{-7} \mathrm{M}\right)$ or FP $\left(10^{-9} \mathrm{M}\right)$ prevented the degradation of IKB- $\alpha$ and decreased the translocation of p65. These effects were even more pronounced when the combination therapy was used (Fig. 7b). For determination of the activity of NF-kB by electrophoretic mobility shift assay experiments, nuclear proteins were subjected to a reaction containing biotin-conjugated oligonucleotides NF- $\mathrm{KB}$ (p65). Salmeterol $\left(10^{-7} \mathrm{M}\right)$ and FP $\left(10^{-9} \mathrm{M}\right)$ attenuates the activity of NF-KB, and in combination, the suppressive effects was increased (Fig. 7c).

\section{Expression of MKP-1 and translocation of GR $\alpha$}

It has been reported that MKP-1 suppresses the MAP kinase pathway (Fig. 9). Therefore, the role of MKP-1 was investigated by Western blot analysis. MKP-1 expression was slightly increased by either CSM, salmeterol, FP, or the combination of the drugs (Fig. 8a). Co-administration of CSM with either salmeterol or FP did not increase the expression of MKP-1. However, administration of CSM with the combination of the drugs did further increased MKP-1 expression. Moreover, it has been reported that glucocorticoids induce MKP-1 to suppress the MAP kinase pathways $[25,26]$ (Fig. 9). An increase in the translocation of GR $\alpha$ and the subsequent stimulation of this receptor could explain the increased MKP-1 expression and the decrease of IL-8 production.

CSM did not affect mRNA expression of GR $\alpha$. Salmeterol or FP slightly increases the mRNA expression with or without CSM. Interestingly, the combination of both drugs with CSM further increased GR mRNA production (Fig. 8b). These data were further confirmed by the translocation of the GR $\alpha$. High amounts of GR $\alpha$ were present in the cytoplasm of the neutrophils under basal

a
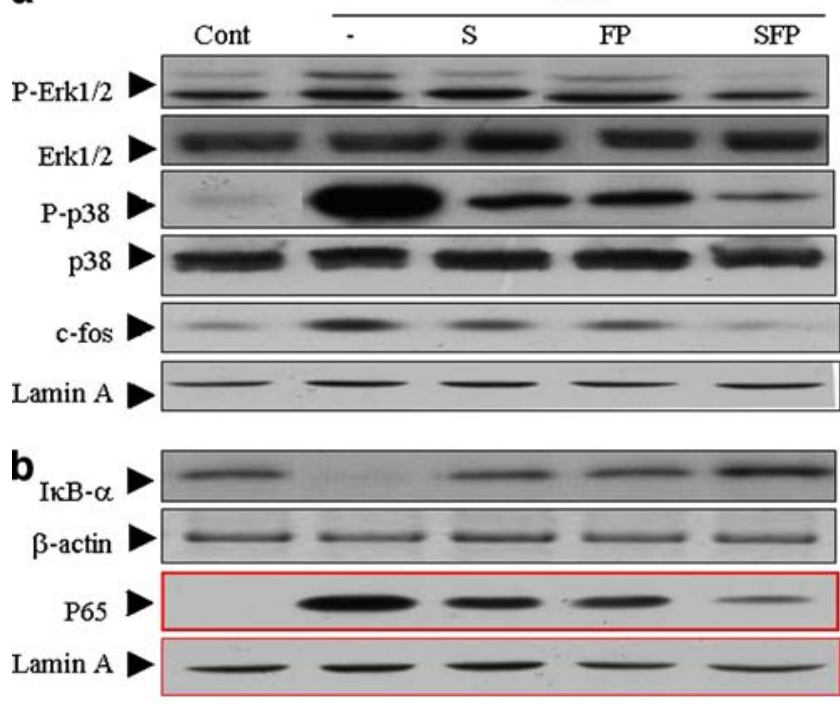

C

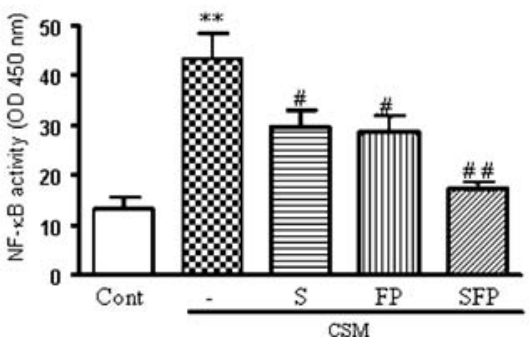

Fig. 7 Intervention of the MAP-kinase and NF-KB pathways. Neutrophils were activated with CSM and drugs as described in material and methods "Materials and methods." Western blot analysis for MAPK pathway; Erk1/2, phospho p38 from whole cell extracts $(50 \mu \mathrm{g})$ and $\mathrm{c}-f o s(25 \mu \mathrm{g})$ from nuclear extracts (a) and NF-KB pathway; IкB- $\alpha$ from whole cell extracts and p65 from nuclear extracts (b) were carried out with related antibodies. Representative results of three independent experiments are shown. $\beta$-actin and Lamin A served as loading controls from cytoplasm and nuclear fractions, respectively. c Neutrophils were preincubated with $\mathrm{S}$ $\left(10^{-7} \mathrm{M}\right)$ or FP $\left(10^{-9} \mathrm{M}\right)$ or in combination for $90 \mathrm{~min}$ and then activated with CSM (0.06 OD) for $30 \mathrm{~min}$ and then the nuclear proteins were analyzed in triplicate for the DNA binding activity of $\mathrm{NF}-\mathrm{KB}$ using the kit. NF- $\mathrm{KB}$ activation is evaluated with reading optical density at $450 \mathrm{~nm}$. Values (mean \pm SEM) are representative data from one of five independent sets of experiments. Asterisk indicates significant differences between medium-treated cells and cells treated with CSM $\left({ }^{*} p<0.05\right)$, and the number sign represents the significance differences between cells treated with CSM and $S$ or FP $\left({ }^{\#} p<0.05\right.$, $\left.{ }^{\# \#} p<0.01\right)$. $S$ and $F P$ indicate for salmeterol and FP, respectively 
a
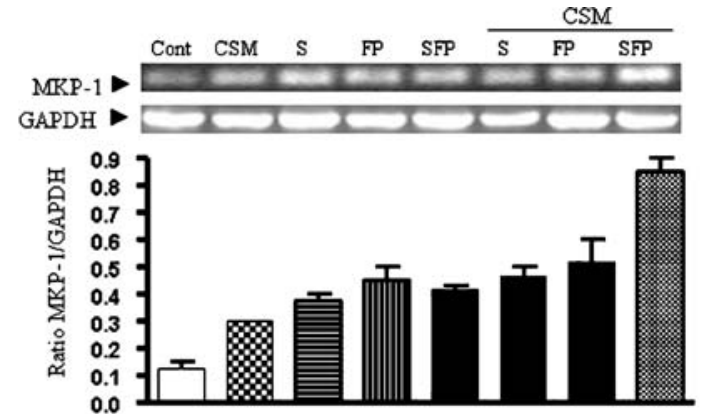

b
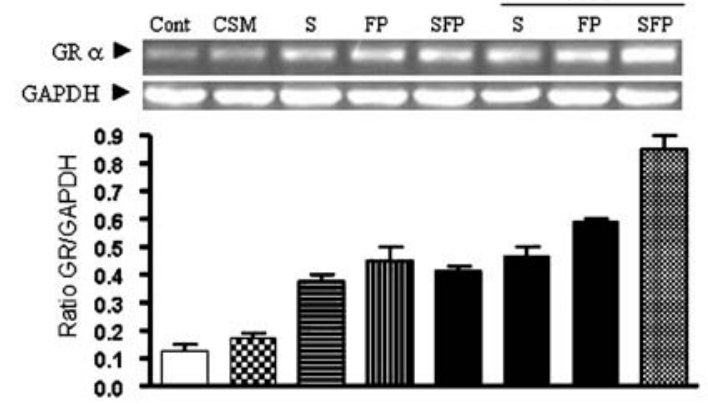

c

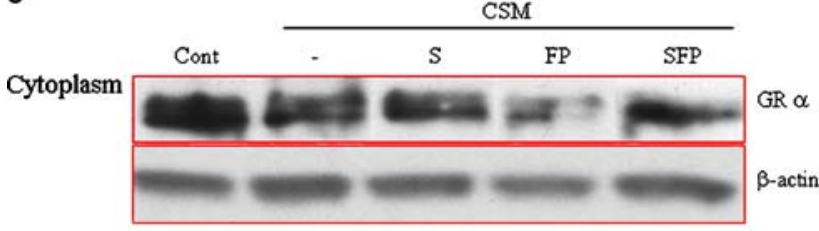

Nucleus

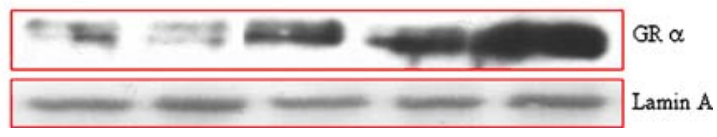

Fig. 8 mRNA expression of MKP-1, GR $\alpha$ and translocation of GR $\alpha$. Neutrophils were pretreated with salmeterol and FP or in combination for $15 \mathrm{~min}$ and then activated for $30 \mathrm{~min}$ for mRNA level of MKP-1 and GR $\alpha$. Total RNA was isolated and subjected to RT-PCR using specific primers for MKP-1 (a) or for GR $\alpha$ (b). Glyceraldehyde-3phosphate dehydrogenase (GAPDH) served as loading housekeeping control gene. Lower graphs $\mathrm{a}$ and $\mathrm{b}$ depicted for quantitative expression of MKP-1 and GR $\alpha$ mRNA, as a ratio to GAPDH mRNA. Representative results of three independent experiments are shown. c Neutrophils were pretreated with salmeterol or FP or in combination for $90 \mathrm{~min}$ and then activated with CSM (0.06 OD) for $30 \mathrm{~min}$ to determine GR $\alpha$ cytoplasmic and nuclear expression at protein levels. $\beta$-Actin and Lamin A served as loading controls from cytoplasm and nuclear fractions, respectively. Representative results of three independent experiments are shown. $S$ and $F P$ indicated for salmeterol and FP, respectively

conditions, which was not affected by CSM stimulation (Fig. 8c). Salmeterol and FP increased the transport of GR $\alpha$ to the nucleus. This effect was strongly enhanced when the combination of the drugs were used (Fig. 8c).

\section{Discussion}

Neutrophils and neutrophil elastase, metalloproteases, and oxidants have all been shown to play a role in the pathogenesis of emphysema [27]. Current concepts suggest that the pathogenesis of emphysema is an imbalance between proteases and anti-proteases in the lung [28]. IL8 is chemotactic for neutrophils and can activate these cells. Elevated levels of IL-8 have been found in the bronchoalveolar lavage fluid of smokers and COPD patients that correlated positively with neutrophil counts in the lung [29].

A combination therapy using long acting $\beta_{2}$-agonists and glucocorticoids have been shown to be beneficial for COPD patients in several studies [10, 30]. However, no study provided a clear explanation for the additional effect when the combination therapy was used. The goal of this project was to investigate possible mechanisms. As an experimental system, the human neutrophils were exposed to CSM in vitro. CSM induces the release of significant amounts of IL-8, an effect which is not due to LPS contamination [16]. Interestingly, CSM also induced the release of elastase, MMP-2, and MMP-9. Earlier studies have evaluated the effects of CSM on the production of IL8 by pro-inflammatory cells [16, 31-34]. For example, A549 epithelial cell releases comparable amount of IL-8 as neutrophils; however, the epithelial cells were stimulated for $72 \mathrm{~h}$ with CSM and the neutrophils for $9 \mathrm{~h}$.

Thus, in the present study, we used neutrophils for investigation, as they have primary cellular mediators of an acute inflammation and capable of producing proteases including MMPs that degrades the protein components in the extracellular matrix and cause damage to the lung. Recently, it has been demonstrated that increased amounts of MMPs and especially MMP-9 are found in bronchoalveolar lavage fluid from COPD patients and mice that were exposed to CS $[6,35]$. Both salmeterol and FP were able to suppress the CSM-induced IL-8 release, but not the release of elastase and MMP-2 and MMP-9. This may explain the fact that these agents are effective in COPD but do not stop the progression of this disease. As we [14] and others [36, 37] have shown, salmeterol and FP suppress the production of IL-8 in pro-inflammatory cells. There is some controversy in literature. Fluticasone but not salmeterol is effective in reducing CSM-induced IL-8 production by human airway smooth muscle cells [37]. Therefore, it seems that the effects of salmeterol and FP on the regulation of IL-8 are cell specific. The concentrations of the drugs that we used correspond with that used for clinical purpose [38].

We found that, when the neutrophils were incubated with both salmeterol and FP, an additive effect was observed in the suppression of IL-8 production.

To find a possible explanation for this observation, we first investigated the role of CXCR1 and CXCR2 receptors. Neutrophils are stimulated, activated, and recruited through upregulation and binding of a number of $\mathrm{CXC}$ chemokines 
to their complementary receptors, notably CXCR1 and CXCR2 [39-41]. Indeed, CSM increased the surface expression of CXCR1 and CXCR2 receptors. This might be due to a direct effect of CSM, but may also be due to mediators released by the neutrophil itself, such as IL-8. However, salmeterol, FP, or the combination was unable to modify the CSM-induced increase of CXCR1 and CXCR2 receptor expressions. The enhancement of CXCR1 and CXCR2 receptors may be the mechanism for the increase in IL-8 production seen after CSM stimulation; it does not clarify the additive effect in suppressing IL- 8 production observed after the combination therapy. In an attempt to find another explanation, the role of ROS was investigated. In response to a variety of stimuli, neutrophils release large amount of ROS generated by NADPH oxidase. We found two lines of evidence to suggest that ROS might be involved in the CSM-induced IL-8 production in neutrophils. Firstly, the ROS scavenger NAC almost completely inhibited the IL-8 production. Secondly, neutrophils produce significant amounts of ROS upon CSM stimulation. However, the combination therapy did not affect the ROS production. Therefore, an explanation for the additive effect of the combination therapy was sought downstream from CXCR and the production of ROS (Fig. 9).

ROS are able to activate the NF-KB/MAPK pathways and, hence, cause the production of IL-8. Pharmacological agents that influenced these pathways, curcumin, SN50, SB239063, and PD98059, were able to inhibit CSMinduced IL-8 production that suggests the involvement of NF-KB, p38 MAP kinase and Erk1/2, respectively. The involvement of these proteins was further confirmed with molecular biology studies. A key finding was that the combination of salmeterol and FP abrogates the phosphorylation of Erk1/2, p38, c-fos (Fig. 7). Moreover, CSM induced the degradation of IKB- $\alpha$ in cytoplasm and increases the translocation of p65 in nuclear fraction. Both salmeterol and FP prevented the degradation of IKB- $\alpha$ and decreased the translocation of $\mathrm{p} 65$. These effects were even more pronounced when the combination therapy was used. It can be concluded that both the NF-kB- and MAPK pathways are involved. The mechanism by which these agents can have an additive effect and affect both pathways

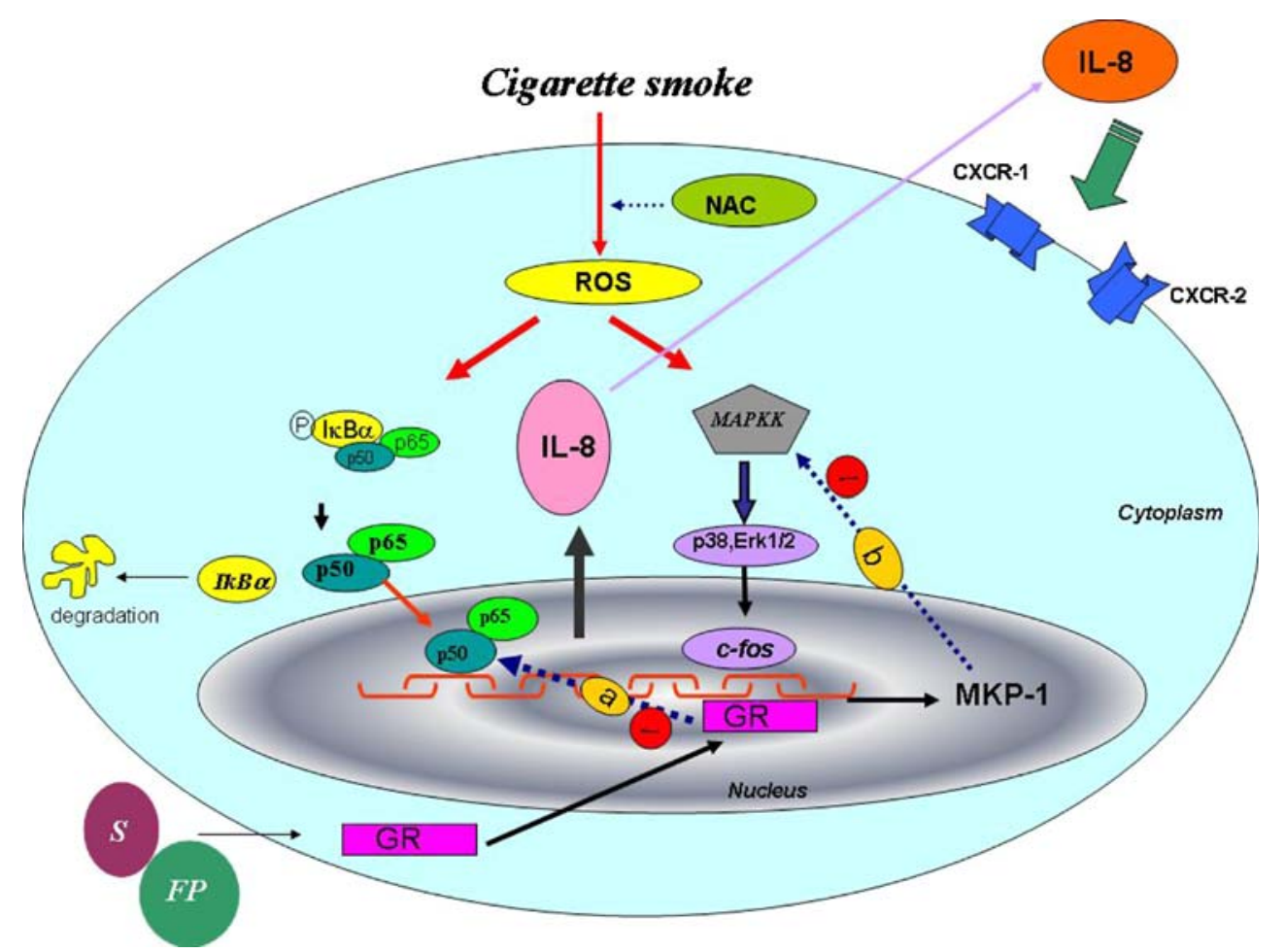

Fig. 9 Schematic diagram of IL-8 production by neutrophils. CSE by inducing ROS inside the cells activates MAPK and NF- $\mathrm{kB}$ pathways to induce IL- 8 expression and release. Release of IL- 8 can activate CXCR1 and CXCR2 receptors. Upon interaction of FP and salmeterol with the GR $\alpha$, this receptor is transported into the nucleus where it binds to discreet nucleotide sequences to alter the expression of specific genes. a A rapid effect of the receptor has also been reported in the negative regulation of the action of transcription factors such as AP-1 or NF-kB. A completely different mechanism by which GR might exert its anti-inflammatory effects is the inhibition of the signaling pathways that regulate inflammatory processes, in particular the Erk-1 and Erk-2 pathways. b Glucocorticoids first increase the expression of MKP-1 gene at the promoter level. This phosphatase is known to inactivate MAP kinases. MKP-1 induction alone is, however, not sufficient to inhibit Erk-1/2. After treatment, glucocorticoids exert a second action by attenuating proteasomal degradation of MKP-1 
remains unclear. Therefore, we set experiments to elucidate the molecular events in details. Glucocorticoids are well known for their anti-inflammatory, immune-suppressive, and anti-allergic actions [30, 42-44]. The human glucocorticoid receptor (hGR) gene encodes two protein isoforms: (a) the cytoplasmic alpha form (GR $\alpha)$, which binds hormones, translocates to the nucleus, and regulates gene transcription and (b) the nuclear localized beta isoform (GR $\beta)$, which does not bind to known ligands and attenuates GR $\alpha$ action [7, 45-47].

The complicity of GR receptors to the agonist is not well described. hGR $\beta$ can inhibit the actions of hGR $\alpha[46,48]$. Increased expression of the dominant-negative hGR $\beta$ in inflammatory cells may be a potential mechanism for ablating the anti-inflammatory effects of glucocorticoids and inducing glucocorticoid resistance [7, 49].

Moreover, GR $\alpha$ negatively regulates the action of transcription factors such as AP- $1 / \mathrm{c}-f o s$ or NF-kB [50-54] (Fig. 9, pathway a). As these transcription factors control the expression of numerous pro-inflammatory genes, the inhibition of their activity by GR has become a paradigm for the anti-inflammatory action of glucocorticoids. A completely different mechanism by which GR might exert its inflammatory processes, in particular, the extracellularregulated kinases (Erk)-1 and -2 pathways. Glucocorticoids have been shown previously to induce the expression of MKP-1, a dual specificity phosphatase that potently inactivates all MAPKs [26] (Fig. 9, pathway b). Surprisingly, the combination therapy additively increased MKP-1 expression in the presence of CSM. A possible explanation for the increased expression of MKP-1 and the decreased phosphorylation of the proteins in the NF-kB-pathway could be an increased expression and translocation of the GR $\alpha$ (Fig. 9). Salmeterol and FP increased the translocation of the GR $\alpha$ to the nucleus in the presence of CSM. A clear increased translocation of the GR $\alpha$ was found when the agents were combined in the presence of CSM.

The above-mentioned explanation is an over simplification and is only used as working hypothesis. Indeed, most of signal transduction pathways have complex networks, and in this study, we investigate a link between translocation of NF-KB and GR in suppression of IL-8 releases. We cannot exclude other events, as post-transcriptional modifications of GRs and cross-talk between GR signaling with other signaling pathways have been found to play a pivotal role in cell- and gene-specific transcriptional regulation. Moreover, impact of our data should be verified by in vivo models by using knock out animal in GRs.

In conclusion, the CSM-induced increased expression of CXCR and the production of ROS might explain the enhanced IL-8 production by human neutrophils in vitro. The increased expression of CXCR, the production of ROS, and the release of elastase and MMP-2 and MMP-9 were not influenced by salmeterol, FP, or the combination. However, the combination therapy had an additive suppressive effect on the CSM-induced production of IL- 8 . The latter could be explained by an increased expression by the combination therapy of MKP-1 and the GR receptor and the increased translocation of the GR receptor to the nucleus. This leads eventually to the suppression of both the NF-KB and MAPK pathways (Fig. 9).

Acknowledgments This study was supported by Division of Pharmacology and Pathophysiology, Utrecht Institute for Pharmaceutical Sciences (UIPS), Utrecht University, The Netherlands and GlaxoSmithKline Research and Development, UK.

Open Access This article is distributed under the terms of the Creative Commons Attribution Noncommercial License which permits any noncommercial use, distribution, and reproduction in any medium, provided the original author(s) and source are credited.

\section{References}

1. Barnes PJ (2006) Corticosteroid effects on cell signalling. Eur Respir J 27:413-426

2. Calverley PM, Walker P (2003) Chronic obstructive pulmonary disease. Lancet 362:1053-1061

3. Yoshida T, Tuder RM (2007) Pathobiology of cigarette smokeinduced chronic obstructive pulmonary disease. Physiol Rev 87:1047-1082

4. Valenca SS, Castro P, Pimenta WA, Lanzetti M, Silva SV, BarjaFidalgo C, Koatz VL, Porto LC (2006) Light cigarette smokeinduced emphysema and NFkappaB activation in mous.e lung. Int J Exp Pathol 87:373-381

5. Pohl W [The pathobiology of COPD]. Wien.Med Wochenschr. $155: 85-89$

6. Mercer PF, Shute JK, Bhowmik A, Donaldson GC, Wedzicha JA, Warner JA (2005) MMP-9, TIMP-1 and inflammatory cells in sputum from COPD patients during exacerbation. Respir Res 6:151

7. de CM, Elliot S, Kino T, Bamberger C, Karl M, Webster E, Chrousos GP (1996) The non-ligand binding beta-isoform of the human glucocorticoid receptor (hGR beta):tissue levels, mechanism of action, and potential physiologic role. Mol Med 2:597-607

8. Babusyte A, Stravinskaite K, Jeroch J, Lotvall J, Sakalauskas R, Sitkauskiene B (2007) Patterns of airway inflammation and MMP-12 expression in smokers and ex-smokers with COPD. Respir Res 8:81

9. Srivastava PK, Dastidar SG, Ray A (2007) Chronic obstructive pulmonary disease: role of matrix metalloproteases and future challenges of drug therapy. Expert Opin Investig Drugs 16:10691078

10. Bourbeau J, Christodoulopoulos P, Maltais F, Yamauchi Y, Olivenstein R, and Hamid Q (2007) Effect of salmeterol/ fluticasone propionate on airway inflammation in COPD:a randomized controlled trial. Thorax

11. Celli BR, Barnes PJ (2007) Exacerbations of chronic obstructive pulmonary disease. Eur Respir J 29:1224-1238

12. Usmani OS, Ito $\mathrm{K}$, Maneechotesuwan $\mathrm{K}$, Ito $\mathrm{M}$, Johnson $\mathrm{M}$, Barnes PJ, Adcock IM (2005) Glucocorticoid receptor nuclear translocation in airway cells after inhaled combination therapy. Am J Respir Crit Care Med 172:704-712 
13. Pearlman DS, Stricker W, Weinstein S, Gross G, Chervinsky P, Woodring A, Prillaman B, Shah T (1999) Inhaled salmeterol and fluticasone:a study comparing monotherapy and combination therapy in asthma. Ann Allergy Asthma Immunol 82:257-265

14. Sarir H, Mortaz E, Karimi K, Johnson M, Nijkamp FP, Folkerts G (2007) Combination of fluticasone propionate and salmeterol potentiates the suppression of cigarette smoke-induced IL- 8 production by macrophages. Eur J Pharmacol 19(7):66

15. Kuijpers TW, Tool AT, van der Schoot CE, Ginsel LA, Onderwater JJ, Roos D, Verhoeven AJ (1991) Membrane surface antigen expression on neutrophils: a reappraisal of the use of surface markers for neutrophil activation. Blood 78: $1105-1111$

16. Karimi K, Sarir H, Mortaz E, Smit JJ, Hosseini H, De Kimpe SJ, Nijkamp FP, Folkerts G (2006) Toll-like receptor-4 mediates cigarette smoke-induced cytokine production by human macrophages. Respir Res 7:66

17. Mortaz E, Redegeld FA, Sarir H, Karimi K, Raats D, Nijkamp FP, Folkerts G (2007) Cigarette smoke stimulates the production of chemokines in mast cells. J Leukoc Biol 83(3):575-80

18. van Eijl S, van Oorschot R, Olivier B, Nijkamp FP, Bloksma N (2006) Stress and hypothermia in mice in a nose-only cigarette smoke exposure system. Inhal.Toxicol 18:911-918

19. Baggiolini M (2001) Chemokines in pathology and medicine. J Intern Med 250:91-104

20. Royall JA, Ischiropoulos H (1993) Evaluation of 2',7'-dichlorofluorescin and dihydrorhodamine 123 as fluorescent probes for intracellular $\mathrm{H}_{2} \mathrm{O}_{2}$ in cultured endothelial cells. Arch Biochem Biophys 302:348-355

21. Mortaz E, Redegeld FA, Nijkamp FP, Engels F (2005) Dual effects of acetylsalicylic acid on mast cell degranulation, expression of cyclooxygenase-2 and release of pro-inflammatory cytokines. Biochem Pharmacol 69:1049-1057

22. Planey SL, Abrams MT, Robertson NM, Litwack G (2003) Role of apical caspases and glucocorticoid-regulated genes in glucocorticoid-induced apoptosis of pre-B leukemic cells. Cancer Res 63:172-178

23. Park CB, Takemura A, Aluru N, Park YJ, Kim BH, Lee CH, Lee YD, Moon TW, and Vijayan MM (2007). Tissue-specific suppression of estrogen, androgen and glucocorticoid receptor gene expression in feral vitellogenic male Mozambique tilapia. Chemosphere.

24. Pryor WA, Stone K (1993) Oxidants in cigarette smoke. Radicals, hydrogen peroxide, peroxynitrate, and peroxynitrite. Ann N Y Acad Sci 686:12-27

25. Chen P, Li J, Barnes J, Kokkonen GC, Lee JC, Liu Y (2002) Restraint of proinflammatory cytokine biosynthesis by mitogenactivated protein kinase phosphatase-1 in lipopolysaccharidestimulated macrophages. J Immunol 169:6408-6416

26. Lasa M, Abraham SM, Boucheron C, Saklatvala J, Clark AR (2002) Dexamethasone causes sustained expression of mitogenactivated protein kinase (MAPK) phosphatase 1 and phosphatase-mediated inhibition of MAPK p38. Mol Cell Biol 22: 7802-7811

27. Pease JE, Sabroe I (2002) The role of interleukin-8 and its receptors in inflammatory lung disease: implications for therapy. Am J Respir Med 1:19-25

28. Stockley RA (1999) Neutrophils and protease/antiprotease imbalance. Am J Respir Crit Care Med 160:S49-S52

29. Tanino M, Betsuyaku T, Takeyabu K, Tanino Y, Yamaguchi E, Miyamoto K, Nishimura M (2002) Increased levels of interleukin8 in BAL fluid from smokers susceptible to pulmonary emphysema. Thorax 57:405-411

30. Barnes PJ (2002) Scientific rationale for inhaled combination therapy with long-acting beta2-agonists and corticosteroids. Eur Respir J 19:182-191
31. Yang SR, Chida AS, Bauter MR, Shafiq N, Seweryniak K, Maggirwar SB, Kilty I, Rahman I (2006) Cigarette smoke induces proinflammatory cytokine release by activation of NF-kappaB and posttranslational modifications of histone deacetylase in macrophages. Am J Physiol Lung Cell Mol Physiol 291:L46L57

32. Kode A, Yang SR, Rahman I (2006) Differential effects of cigarette smoke on oxidative stress and proinflammatory cytokine release in primary human airway epithelial cells and in a variety of transformed alveolar epithelial cells. Respir Res $7: 132$

33. Mio T, Romberger DJ, Thompson AB, Robbins RA, Heires A, Rennard SI (1997) Cigarette smoke induces interleukin-8 release from human bronchial epithelial cells. Am J Respir Crit Care Med 155:1770-1776

34. Masubuchi T, Koyama S, Sato E, Takamizawa A, Kubo K, Sekiguchi M, Nagai S, Izumi T (1998) Smoke extract stimulates lung epithelial cells to release neutrophil and monocyte chemotactic activity. Am J Pathol 153:1903-1912

35. Leclerc O, Lagente V, Planquois JM, Berthelier C, Artola M, Eichholtz T, Bertrand CP, Schmidlin F (2006) Involvement of MMP-12 and phosphodiesterase type 4 in cigarette smokeinduced inflammation in mice. Eur Respir J 27:1102-1109

36. MacRedmond RE, Greene CM, Dorscheid DR, McElvaney NG, O'Neill SJ (2007) Epithelial expression of TLR4 is modulated in COPD and by steroids, salmeterol and cigarette smoke. Respir Res 8:84

37. Oltmanns U, Walters M, Sukkar M, Xie S, Issa R, Mitchell J, Johnson M, Chung KF (2008) Fluticasone, but not salmeterol, reduces cigarette smoke-induced production of interleukin- 8 in human airway smooth muscle. Pulm Pharmacol Ther 21: 292-297

38. Piatti G, Ambrosetti U, Santus P, Allegra L (2005) Effects of salmeterol on cilia and mucus in COPD and pneumonia patients. Pharmacol Res 51:165-168

39. Qiu Y, Zhu J, Bandi V, Atmar RL, Hattotuwa K, Guntupalli KK, Jeffery PK (2003) Biopsy neutrophilia, neutrophil chemokine and receptor gene expression in severe exacerbations of chronic obstructive pulmonary disease. Am J Respir Crit Care Med 168:968-975

40. Lee J, Horuk R, Rice GC, Bennett GL, Camerato T, Wood WI (1992) Characterization of two high affinity human interleukin8 receptors. J Biol Chem 267:16283-16287

41. de Boer WI, Sont JK, van Schadewijk A, Stolk J, van Krieken JH, Hiemstra PS (2000) Monocyte chemoattractant protein 1, interleukin 8, and chronic airways inflammation in COPD. J Pathol 190:619-626

42. Adcock IM, Stevens DA, Barnes PJ (1996) Interactions of glucocorticoids and beta 2-agonists. Eur Respir J 9:160-168

43. Yamamoto KR (1985) Steroid receptor regulated transcription of specific genes and gene networks. Annu Rev Genet 19:209-252

44. Beato M (1989) Gene regulation by steroid hormones. Cell 56:335-344

45. Oakley RH, Sar M, Cidlowski JA (1996) The human glucocorticoid receptor beta isoform. Expression, biochemical properties, and putative function. J Biol Chem 271:9550-9559

46. Charmandari E, Chrousos GP, Ichijo T, Bhattacharyya N, Vottero A, Souvatzoglou E, Kino T (2005) The human glucocorticoid receptor (hGR) beta isoform suppresses the transcriptional activity of hGRalpha by interfering with formation of active coactivator complexes. Mol Endocrinol 19:52-64

47. Pratt WB (1993) The role of heat shock proteins in regulating the function, folding, and trafficking of the glucocorticoid receptor. J Biol Chem 268:21455-21458

48. Hollenberg SM, Weinberger C, Ong ES, Cerelli G, Oro A, Lebo R, Thompson EB, Rosenfeld MG, Evans RM (1985) 
Primary structure and expression of a functional human glucocorticoid receptor cDNA. Nature 318:635-641

49. Giguere V, Hollenberg SM, Rosenfeld MG, Evans RM (1986) Functional domains of the human glucocorticoid receptor. Cell $46: 645-652$

50. Liden J, Delaunay F, Rafter I, Gustafsson J, Okret S (1997) A new function for the C-terminal zinc finger of the glucocorticoid receptor. Repression of RelA transactivation. J Biol Chem 272:21467-21472

51. Heck S, Kullmann M, Gast A, Ponta H, Rahmsdorf HJ, Herrlich P, Cato AC (1994) A distinct modulating domain in glucocorticoid receptor monomers in the repression of activity of the transcription factor AP-1. EMBO J 13:4087-4095
52. Nissen RM, Yamamoto KR (2000) The glucocorticoid receptor inhibits NFkappaB by interfering with serine-2 phosphorylation of the RNA polymerase II carboxy-terminal domain. Genes Dev 14:2314-2329

53. Jonat C, Rahmsdorf HJ, Park KK, Cato AC, Gebel S, Ponta H, Herrlich P (1990) Antitumor promotion and antiinflammation: down-modulation of AP-1 (Fos/Jun) activity by glucocorticoid hormone. Cell 62:1189-1204

54. Yang-Yen HF, Chambard JC, Sun YL, Smeal T, Schmidt TJ, Drouin J, Karin M (1990) Transcriptional interference between c-Jun and the glucocorticoid receptor: mutual inhibition of DNA binding due to direct protein-protein interaction. Cell 62: $1205-1215$ 